\title{
Rain forest in Mexico: research and conservation at Los Tuxtlas
}

Alejandro Estrada and Rosamond Coates-Estrada

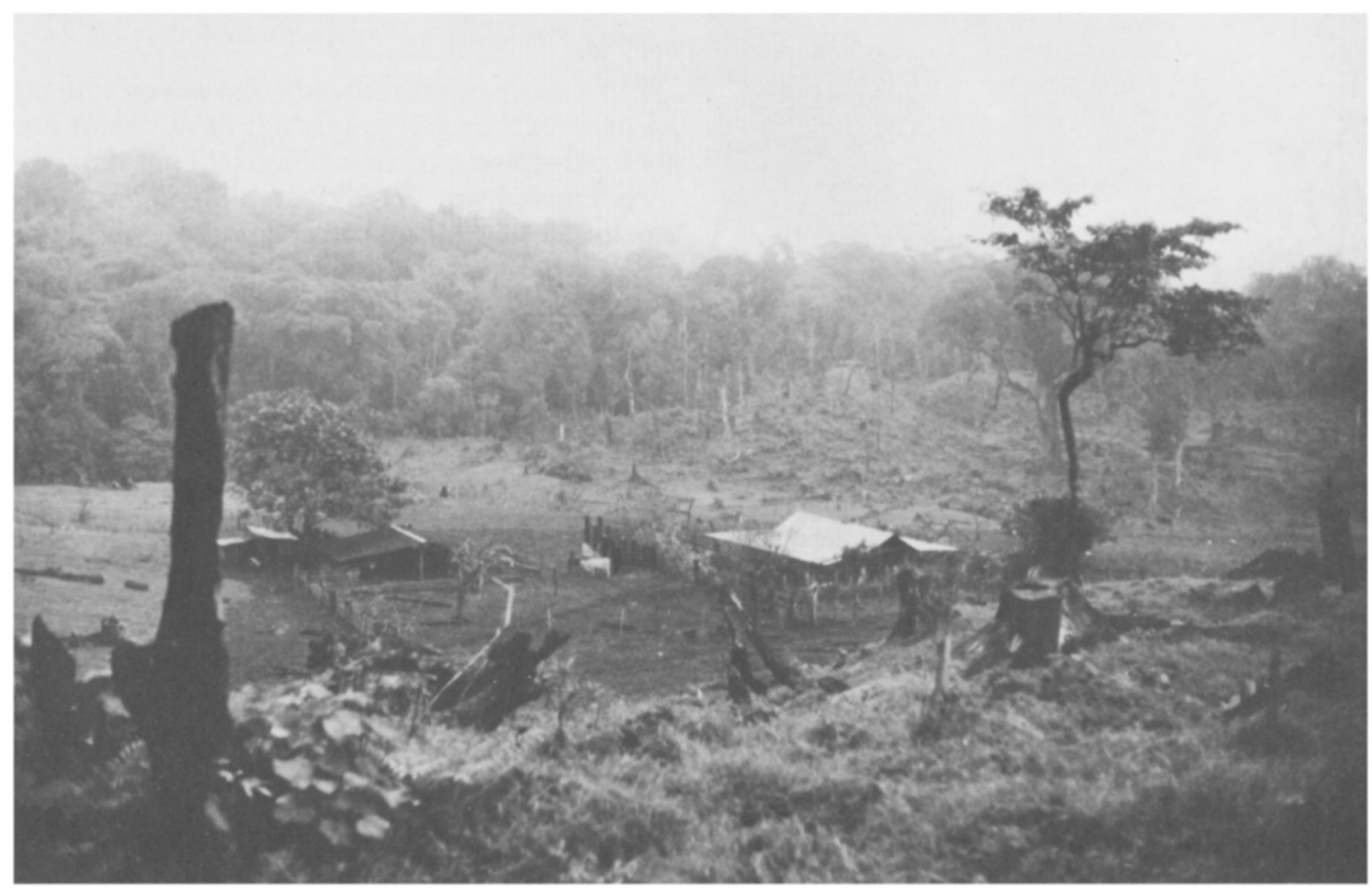

The rain forests of southern Mexico represent the northernmost extent of this ecosystem in the Americas. In the past 30 years half of these forests have been destroyed; only three patches remain where once forest stretched unbroken from Veracruz to Chiapas. But at a university research station set up in 1967 something is being done. The authors, who work at the station, describe the conservation, research and education taking place there and the important role the station has in persuading the community of the necessity of conserving the country's rain forests.

Mexico's tropical rain forests, which c.ccur in the southern states of Veracruz, Tabasco, Campeche and Chiapas, are estimated to have once covered 


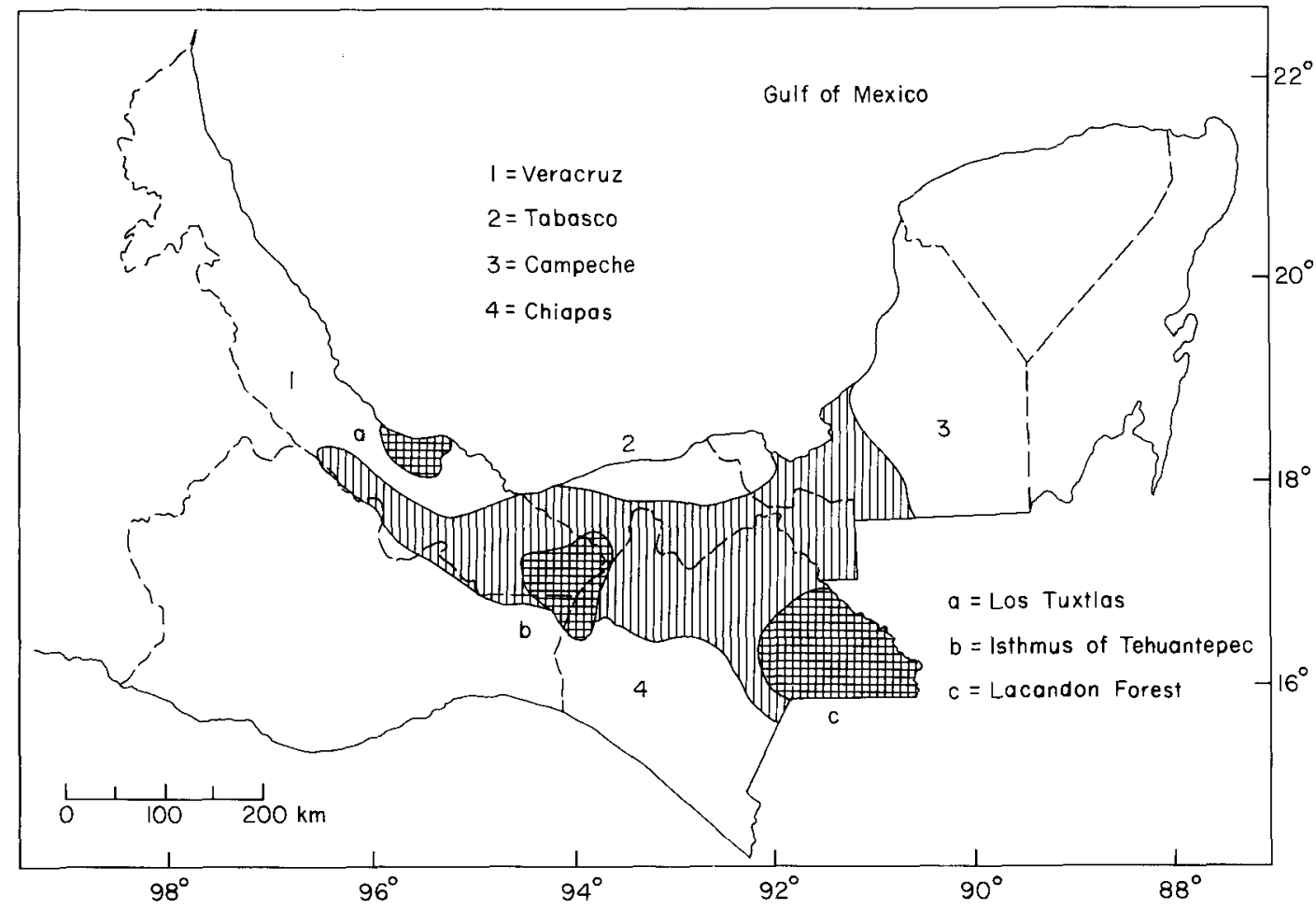

Southern Mexico showing the past distribution (shaded areas) of the tropical rain forest of which only large and small islands remain. Of the large islands the three indicated by the cross-hatched pattern stand out as a result of their size.

$110,000 \mathrm{sq} \mathrm{km}$, or six per cent of the country. But in the past 30 years at least 50 per cent has been destroyed-for crops such as sugar cane, coffee and corn, for timber (using non-selective logging methods) and for cattle ranching. More recently, oil exploration and discovery in the states of Tabasco, Campeche and northern Chiapas have significantly added to the massive destruction of lowland forest. What once used to be a continuous corridor of rain forest from Veracruz to Chiapas is now a series of large and small islands of forest (see map). The only remaining substantial rain forest in the 13,000-sq-km Lacandon Forest near Mexico's southern border, which is of especial significance in that it is one of the three large lowland rain forests remaining in Central America. Two smaller patches of tropical moist forest, together totalling some 2000-3000 sq $\mathrm{km}$, are found at the Isthmus of Tehuantepec and at Los Tuxtlas in the state of Veracruz. 202
As much as 30 per cent of the Lacandon Forest near the Guatemalan border is believed to have been eliminated as a result of government colonisation programmes, notably for planned agriculture, and especially for coffee plantations and cattle ranching. However, over $6000 \mathrm{sq} \mathrm{km}$ of the Lacandon Forest have been declared a forest reserve, of which the 3300-sq-km Montes Azules have been set aside as a UNESCO biosphere reserve (Myers, 1980).

The evergreen rain forest that occurs in the south of Veracruz represents the northernmost distribution of the ecosystem in the American continent and very little is known about it. In the past few decades the Instituto de Biologia of the Universidad Nacional Autónoma de México has been developing biological research in various parts of southern Mexico. The establishment of biological reserves that ensure the continuity of the research projects, however, has proceeded at Oryx Vol 17 No 4 


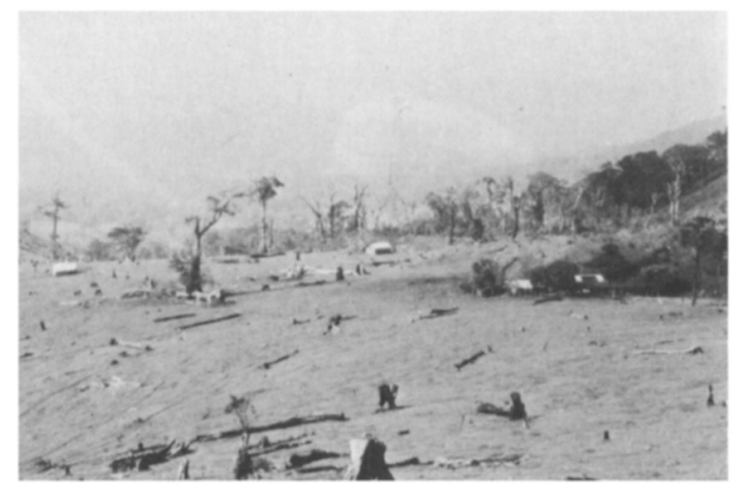

Kain forest destruction in the Lacandon Forest (A. Estrada).

a much slower rate than the disappearance of the rain forest. With the aim of having a permanent research site that could work as a beach-head for conservation and to provide the needed continuity in research, the Instituto de Biología created a research station, Los Tuxtlas, in 1967. Here long-term projects are under way to obtain a detailed knowledge of the species composition of the ecosystem, and to describe and understand ecosystem structure and function with the longterm objective of conserving it and using its resources rationally. Los Tuxtlas is in the eastern part of the range Sierra de Los Tuxtlas, an area of volcanic origin dominated by the San Martin Volcano. It covers 700 ha in which the dominant vegetation type is high evergreen rain forest (Miranda and Hernández, 1963). It consists of a strip of land, $5 \mathrm{~km}$ long and $1.5 \mathrm{~km}$ wide from north to south, connected to an area of about 10,000 ha of rain forest extending toward and around the San Martin Volcano. This latter area was designated as a reserve by the state government in 1980 .

The mean annual rainfall of $4500 \mathrm{~mm}$ is distributed seasonally, with a dry season (when mean monthly precipitation is less than $150 \mathrm{~mm}$ ) from March to May. Mean annual temperature is $27^{\circ} \mathrm{C}$. The reserve's altitudinal range is $160-530 \mathrm{~m}$, but including the volcano extends this to $1500 \mathrm{~m}$, encompassing a variety of vegetational zones. To optimise use of its physical and biotic resources, the research station has been divided into three main zones that serve different purposes: conservation, research and education. The conservation area is a wildlife sanctuary and is continuous with the forest that Rain forest in Mexico

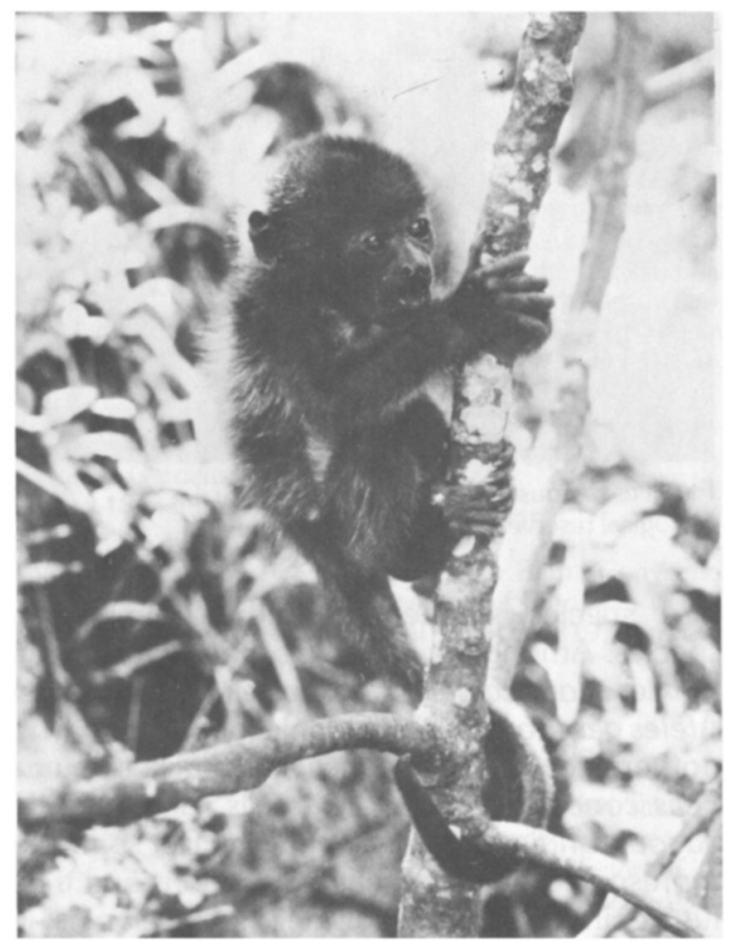

Infant howler monkey, about four weeks old, rescued from poachers who had killed the mother in the forests of Chiapas (A, Estrada).

extends toward the San Martin Volcano. In the eastern section of the reserve a zone has been set aside for research projects and, at the eastern extremity, 6-8 ha of forest form an educational area with a small zoo containing representatives of the local fauna and with a system of trails with signs and labelled plants.

While the dominant ecosystem is the high evergreen rain forest there are also secondary forests where secondary succession is well represented, two lagoons and many streams. A great number of animals, particularly mammals and reptiles, are disappearing in the unprotected rain forest which still remains in southern Mexico, due to illegal hunting and forest destruction. Spider and howler monkeys, paca Cuniculus paca, red brocket deer Mazama americana, jaguar Panthera onca, Baird's tapir Tapirus bairdi and the manatee Trichechus manatus have been hunted so much that they have disappeared from some areas. In the reserve, however, there is still a wide spectrum of animals: 80 mammal species; about 300 


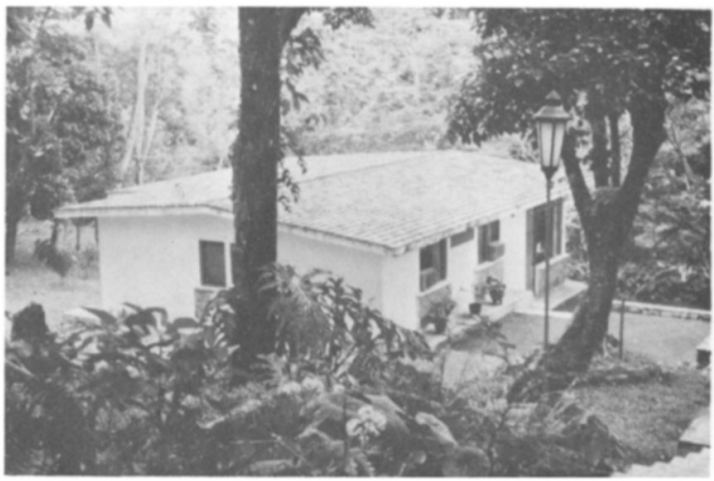

Facilities to house scientists and students at the biological reserve, Los Tuxtlas (A. Estrada).

bird species; 92 reptiles and 50 amphibian species. Among the mammals there are Mexican howler Alouatta palliata and black-handed spider Ateles geoffroyi monkeys, kinkajous Potos flavus, nothern coatis Nasua narica, red brockets, puma Felis concolor, ocelot $F$. pardalis, jaguarundi $F$. yagouarundi and margay $F$. weidi. But some are represented by very small populations and their future in the forest outside the reserve is in danger.

A trail system is used both by the researchers and by the personnel in charge of surveying the forest for illegal hunters and unauthorised visitors. Maps made from aerial photographs depicting the major topographical and ecological features are available to researchers. At the station, the university maintains a number of buildings to house visiting scientists, groups of students and the resident academic staff. In addition there are three laboratories with equipment to process biological material and a building that houses a library, museum and scientific collections such as a herbarium, reptiles, mammals, birds and insects. The research projects taking place at Los Tuxtlas cover many diverse areas: plant taxonomy and plant inventories; plant/animal interactions; reptile ecology and reproductive biology; primate, bird and insect ethology; plant demography, phenology and primary productivity; ecology of arboreal primary consumers (mammals); and dispersal of seeds by mammals and birds.

Every year over 1000 people visit the station, ranging from elementary school children to 204

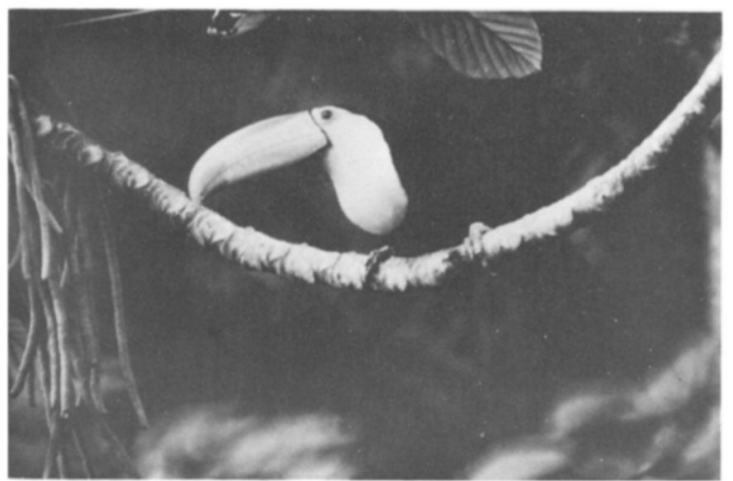

Keel-billed toucan Ramphastos sulfuratus, an ubiquitous inhabitant of the Mexican rain forest (A. Estrada)

graduate students and professionals. This intensity of use attests to the important role the reserve plays in the diffusion of knowledge about the rain forest ecosystem and the need for its conservation. In addition, as part of the educational programme, the station's academic staff publish regular articles in the local newspaper and prepare programmes for local radio. Regular visits are made to the rural communities near the station and illustrated talks given.

The existence of the research station since 1967 and the research and educational activities carried out there are helping to prove that the conservation of a non-renewable resource such as the rain forest (Gomez-Pompa et al., 1972) can be carried out with important benefits for the scientific and public community. In addition it emphasises the need to set aside some of the still remaining large areas of rain forest in Mexico to protect the many plant and animal species existing there so that aspects of their biology can be studied for the benefit of man.

\section{References}

Gomez-Pompa, A., Vazques-Yanez, C. and Guevara, S. 1972. The tropical rain forest: a non-renewable resource. Science 177, 762-764.

Myers, N. 1980. Conversion of Tropical Moist Forests. National Academy of Sciences, Washington, DC.

Miranda, F. and Hernández, E. 1963. Los tipos de vegetación de México y su clasificación. Bol. Soc. Bot. Mex. 29, $29-179$.

A. Estrada and R. Coates-Estrada, Estación de Biología Tropical 'Los Tuxtlas'. Instituto de Biología, UNAM, Apartado Postal 94, San Andres Tuxtla, Veracnuz, México. 